\title{
A Study on Assessment of Relationship between Blood Glucose and Serum Lipids in Patients of Dyslipidemia Receiving Atorvastatin
}

\author{
Authors \\ Gauri Hari Kasabe ${ }^{1}$, Smita Anand Tiwari ${ }^{2}$, Balasaheb Baburao Ghongane ${ }^{3}$ \\ ${ }^{1}$ Assistant Professor, B.J. Government Medical College, Pune, 411001,India \\ ${ }^{2}$ Assistant Professor, B.J. Government Medical College, Pune-41100, India \\ Email: smitamd@gmail.com \\ ${ }^{3}$ Professor and Head of Department, B.J. Government Medical College, Pune, 411001, India \\ Email: ghongane.bb@gmail.com \\ Corresponding Author \\ Gauri Hari Kasabe \\ Sr No.115, Shree Gruhnirman Sanstha, LIG Mhada Colony, Flat No 49 \\ Shivtirthnagar Kothrud Pune-411038, India \\ Email-gauri.kasabe248@gmail.com, Contactno-+91-8007230963
}

\begin{abstract}
Background: Atorvastatin and Lovastatin the most commonly used lipid lowering impair glucose tolerance; Simvastatin reduces insulin secretion while Pravastatin has been shown to increase adiponectin, improving insulin sensitivity and inhibiting gluconeogenesis. For these reasons, in February 2012 the United States Food and Drug Administration mandated labeling changes for all statins except Pravastatin. Objective of the study was to study the relationship between blood glucose and serum lipids in patients of Dyslipidemia receiving Atorvastatin

Methods: A prospective, single center study that was conducted in of total of 60 subjects. Newly diagnosed patients suffering from dyslipidemia, according to NCEP ATP III Guidelines (National Cholesterol Education Program, Adult Treatment Panel III).These are divided in 2 groups ( $n=30$ each). GROUP 1-patients having dyslipidemia with type 2 Diabetes Mellitus and GROUP 2-patients having dyslipidemia without Diabetes Mellitus.

Conclusion: With the results of present study $10 \mathrm{mg} /$ day of Atorvastatin for 6 months did not affect FBG or $P P B G$ in Non-diabetic patients significantly, but there was a significant deterioration in the blood glucose control - fasting and post-prandial, in the diabetic patients after 6 months and 3 months of drug use respectively. Atorvastatin $10 \mathrm{mg}$ is an effective hypolipidemic drug and has adequate lipid lowering effects in diabetic and non-diabetics
\end{abstract}

Key Words: Atorvastatin, Dyslipidemia,bloodglucose, serum lipids, correlation.

\section{Introduction}

"Dyslipidemia" refers to the derangements of one or many of the lipoproteins; elevations of Total Cholesterol (TC), Low Density Lipoprotein (LDL) cholesterol and/or Triglycerides (TG), or low levels of High-Density Lipoprotein (HDL) cholesterol while elevation of lipoproteins alone is labeled as "hyperlipidemia". Atherogenic dyslipidemia refers to a combination of elevated triglycerides and small-dense LDL particles, and low levels of HDL- 
cholesterol ${ }^{[1]}$. Dyslipidemia is an important major risk factor for Coronary Heart Disease (CHD), which is the leading cause of death. The World Health Organization estimates that dyslipidemia is associated with more than half of global cases of ischemic heart disease and more than 5.6 million deaths per year ${ }^{[2]}$. Prevalence of dyslipidemia is high among Indians; it has been increasing steadily over the past few decades .A study by Chandra K S et al concludes that the prevalence of dyslipidemia was associated with low HDL cholesterol and this occurrence was unusually high among patients undergoing coronary artery bypass surgery ${ }^{[3]}$. There are ample studies that have established a direct relationship between dyslipid-emia, cardiovascular disease, and diabetes mellitus ${ }^{[2]}$. Atherogenic dyslipidemia is particularly common in South Asians and has been shown to have a strong association with type 2 diabetes mellitus and Coronary Vascular Disease (CVD), which are the part of the well-known metabolic syndrome 3 . Collaborative Atorvastatin Diabetes Study (CARDS) was conducted in nearly 3000 patients with type 2 diabetes Mellitus, were randomized to Atorvastatin (10 mg) group and placebo group. Atorvastatin reduced the number of major cardiovascular events by $37 \%$ and the rate of stroke by $48 \%{ }^{[2]}$. In animal models, it showed that Atorvastatin and Lovastatin impair glucose tolerance; Simvastatin reduces insulin secretion while Pravastatin has been shown to increase adiponectin, improving insulin sensitivity and inhibiting gluconeogenesis ${ }^{[4]}$. For these reasons, in February 2012 the United States Food and Drug Administration mandated labeling changes for all statins except Pravastatin [5]. Atorvastatin and other statin medications may increase the risk of type 2 diabetes compared to those who did not use the medications. A study by Carter AA et al higher risk of developing type 2 diabetes with Atorvastatin and it also shows that Subjects treated with Atorvastatin were found to have $22 \%$ elevated risk of new-onset diabetes, $18 \%$ elevated risk with Rosuvastatin, and $10 \%$ increased risk with use of Simvastatin. In contrast, participants treated with Fluvastatin were at a $5 \%$ lower risk and Lovastatin a $1 \%$ lower risk of developing type 2 diabetes. The crude event rate for incident diabetes was highest for Atorvastatin (30.70 outcomes per 1000 person years $)^{[4]}$. Another study by Culver A Let al suggested that older women who were taking statins, those who were in menopause, had a higher risk of developing diabetes [6]

Therefore this study was designed to assess the alterations in glycemic control due to Atorvastatin with the aim of finding effective therapeutic choice considering drug and dose. None of the study has explained the correlation between rise in blood glucose level and fall in serum lipid level.

\section{Aim and Objectives}

1. To study the effect of Atorvastatin on blood glucose level and serum lipid level.

2. To study the correlation between fall in serum lipid level and rise in blood glucose level.

3. To define a relationship that can strike a balance between optimum changes in lipid level while minimizing the changes in blood glucose level.

\section{Materials and Methods}

Study was a prospective, single centre study conducted in a B.J. Govt. Medical College and Sassoon General Hospital, Pune. Institutional Ethics Committee approval was obtained (BJMC/IEC/ Pharmac/D-1013126)

Total of 60 subjects were enrolled by purposive sample technique from patients attending the medicine- Diabetes and Hypertension outpatient department (OPD) (Figure-1). A written informed consent was obtained from each subject. Patients of either sex in the age group of 35-60 who were newly diagnosed cases of dyslipidemia were included in study. These patients were screened for presence of dyslipidemia on the basis of laboratory investigations or prior records of the same. Diagnosis of dyslipidemia was done according to NCEP ATP III Guideline (2009 Revision of NCEP Adult Treatment Panel III Guidelines) (National Cholesterol Education Program, Adult Treatment Panel III) (LDL-C $\geq 130 \mathrm{mg} / \mathrm{dl}$, Total cholesterol- 
TC $\geq 200 \mathrm{mg} / \mathrm{dl}$, Triglyceride $>150 \mathrm{mg} / \mathrm{dl}$, deranged VLDL) ${ }^{[7]}$. Patients who fulfilled the study inclusion criteria were enrolled for the trial. Women who are pregnant or plan to become pregnant, breast feeding women, patients with Type 1 diabetes mellitus, severe diabetes (fasting blood glucose > 300mg) and patients with diabetic ketoacidosis were excluded from the study. These were divided into Group-I: Diabetic patients with dyslipidemia; receiving Atorvastatin $10 \mathrm{mg}$ OD at night, receiving standard treatment for diabetes mellitus \{Metformin (500 mg O.D.) and one Sulfonylurea (e.g. Glimepiride - 2 mg O.D.) \} over last 6 months .

Group-2: Non diabetic patients with dyslipidemia; receiving Atorvastatin $10 \mathrm{mg} \mathrm{OD}$, receiving standard treatment for hypertension (Tab. Amlodipine $10 \mathrm{mg}$ O.D. only).

(Where diagnosis of diabetes mellitus was done if fasting blood glucose level more than $126 \mathrm{mg} / \mathrm{dl}$ and Postprandial blood glucose level more than 200 $\mathrm{md} / \mathrm{dl}$ )

Figure 1: Consort chart for the study

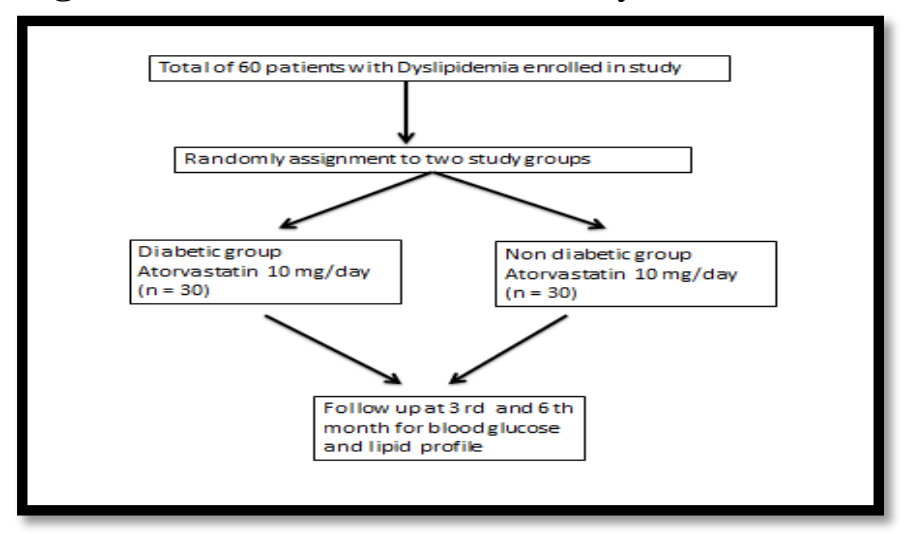

Figure 2: Flow diagram of study:

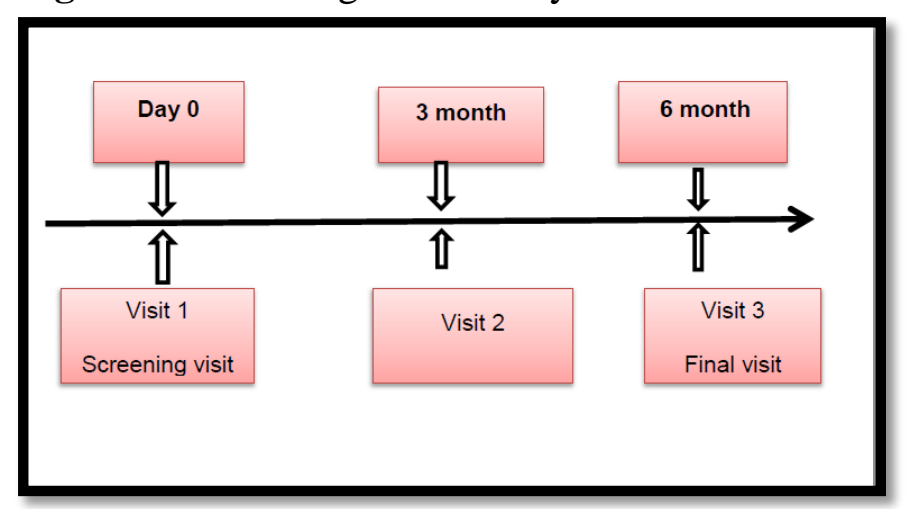

Plan of Study was as shown in Figure-2.At visit 0 (screening visit) the demographic data, like age, weight, height and BMI was recorded .Blood samples were collected for estimation blood glucose (fasting and two hour post-prandial) and lipid profile (LDL, HDL, TG, TC, LDL/ HDL, VLDL) at visit 0 (screening visit), visit1 (three months from baseline) and at visit 2 (6 months from baseline).

\section{Laboratory Investigations ${ }^{[8]}$ :}

The blood samples collected at respective visits were analyzed immediately and those that were not processed immediately were capped and stored at 200c until further analysis. Fasting Blood Glucose (FBG) and post-prandial blood glucose (PPBG) by glucose oxidase method using STAR Diagnostic Kit, Batch no.-E1486, Manufacture date: May 2014 and Expiry date: April 2016.Serum was used for estimation of lipid profile .Total Cholesterol (TC), Low Density Lipoprotein (LDL), High Density Total Cholesterol estimated by using STAR Diagnostic Kit, Batch no.-E -1560, Manufacture date: March 2014 ,Expiry date: August 2016. HDL Cholesterol estimated by using STAR Diagnostic Kit. Batch no.-DHC-141005, Manufacture date: November 2014, Expiry date: January 2016. Triglyceride was estimated by using Autozyme Diagnostic Kit, Batch no.-3605 T, Manufacture date: February 2014, Expiry date: October 2015.Then the LDL/HDL ratio was calculated.

Data was expressed as change in each parameter that was calculated by subtracting value of visit 3from visit 1i.e baseline (value at visit 3-value at visit 1). Percent change was also calculated with respect to baseline value.

\section{Statistical Analysis}

The demographic data like age, weight, height, BMI and biochemical parameters presented as mean +2 standard deviation.(Table-1)

Baseline readings i.e visit 1 were compared with that visit 2 (3 month from baseline) and atvisit 3 (6 month from baseline) respectively. The visit 2 (3 month from baseline) readings were compared with that ofvisit3 (6 month from baseline). This statistical analysis was done for both groups i.e. diabetic and non-diabetic separately. The intra group comparisons that were done in diabetic as well as non-diabetic for biochemical parameters like blood 
glucose level and lipid profile variations, were analyzed using paired student's $t$ test.

The intergroup comparisons for diabetic and nondiabetic group for biochemical parameters like blood glucose level and lipid profile variations were done using the unpaired student's $t$ test.

Graph pad prism 6 and Microsoft excel 2010 were used to do the statistical analysis. The Pearson's correlation co-efficient was applied to analyze the correlation between variations in lipid profile and blood glucose level in each; diabetic and nondiabetic group respectively.

\section{Results}

As shown in Table-1, the two groups receiving Atorvastatin were similar in terms of baseline characteristics as regards the demographic data and lipid profile (TC, LDL ,HDL, TG, VLDL and LDL/HDL ratio ) ( $\mathrm{p}$ value $>0.05$ ). There was a statistically significant difference in the diabetic group (group-1) and non-diabetic group (group-II) as regards the FBG and PPBG ( $p$ value $<0.0001$ ).

In diabetic group receiving Atorvastatin, only when baseline FBG values were compared with that at 6 month there was a significant rise in the reading $(p=0.0021)$. Whereas, when the baseline FBG values were compared with 3 months and 3 months values compared with 6 months there was no significant change observed in the diabetic group. When baseline PPBG values were compared with that at 3months and 6 month respectively there was a significant rise in the reading ( $p$-value $=0.0052$ and p-value $=0.0054$ respectively). (Figure-3) But when the PPBG values at 3 months were compared with 6 months there was no significant change observed in this group. Therefore non-diabetic group did not show any significant change in FBG when their values at baseline they were compared with that at visit 2 and visit 2 values compared with visit 3. (Figure-3). When similar comparisons were done in the non-diabetic group receiving Atorvastatin, it was observed that though there were trends in increase in the FBG yet this was not statistically significant and also the PPBG was not altered much .In diabetic group receiving Atorvastatin, only when baseline FBG values were compared with that at 6 month there was a significant rise in the reading $(\mathrm{p}=0.0021)$. Whereas, when the baseline FBG values were compared with 3 months and 3 months values compared with 6 months there was no significant change observed in the diabetic group. When baseline PPBG values were compared with that at 3months and 6 month respectively there was a significant rise in the reading $(\mathrm{p}$-value $=0.0052$ and $\mathrm{p}$-value $=0.0054$ respectively). (Figure-3) But when the PPBG values at 3 months were compared with 6 months there was no significant change observed in this group. Therefore non-diabetic group did not show any significant change in FBG when their values at baseline they were compared with that at visit 2 and visit 2 values compared with visit 3. (Figure3).When similar comparisons were done in the nondiabetic group receiving Atorvastatin, it was observed that though there were trends in increase in the FBG yet this was not statistically significant and also the PPBG was not altered much.

Figure 3: Effect of Atorvastatin on Fasting and post-prandial Blood Glucose $(\mathrm{mg} / \mathrm{dl})$ in Diabetic and Non-Diabetic Group

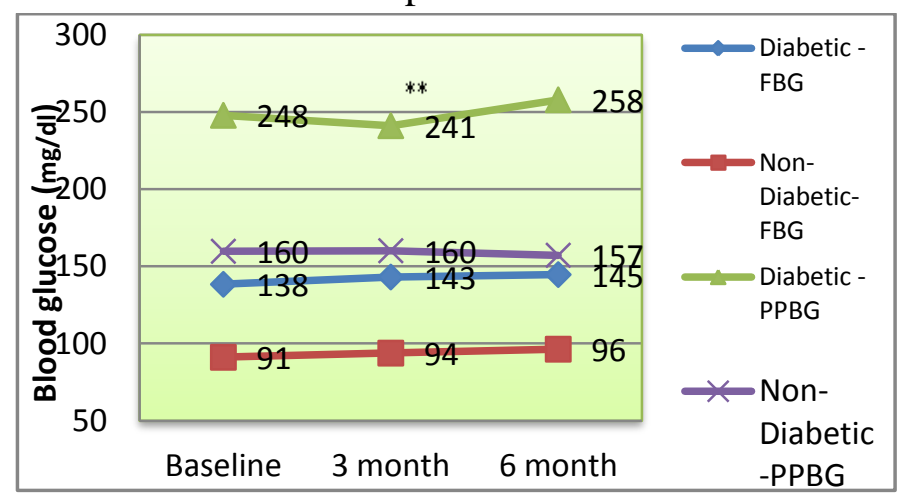

Figures are expressed as mean values $\pm 2 S D .{ }^{*} p-$ value $<0.0021$ when baseline FBG values compared with FBG values at 6 months. ${ }^{* *}$ p-value $<0.0052$ when baseline PPBG values compared with PPBG values at 3 months.*** p-value $<0.0054$ when baseline PPBG values compared with PPBG values at 6 months.

Figure 4 shows effect of Atorvastatin on serum lipid level in Diabetic patients. When baseline values of each - TC, TG, LDL, VLDL and LDL/HDL were compared with their respective values at 3 and 6 months respectively, there was a statically 
significant decrease from the baseline regarding each lipid parameter ( $\mathrm{p}$-value $<0.005$ ). Only when the LDL/HDL ratio and LDL values at 3 months were compared with their respective values at 6 months a statistically significant decrease was noticed. (p- value $<0.005$ ). When the HDL values at baseline were compared with that at 3 months and 6 months respectively, a significant fall in the levels was observed (p-value $<0.003$ and 0.0391 respectively). On the contrary when HDL levels values at 3 months were compared to that at 6 months there was a transient non-significant increase.

Figure 5 shows effect of Atorvastatin on serum lipid level in Non-Diabetic patients. When baseline values of each - TC,TG,LDL, VLDL and LDL/HDL were compared with their respective values at 3 and 6 months respectively, there was a statically significant decrease from the baseline regarding each lipid parameter ( $\mathrm{p}$-value < 0.005). Only when the LDL/HDL ratio, LDL and TC values at 3 months were compared with their respective values at 6 months a statistically significant decrease was noticed. (p- value <0.005). When the HDL values at baseline were compared with that at 6 months and values at 3 months were compared to that at 6 months respectively, a significant rise in the levels was observed (p-value $=0.0002$ and 0.007 respectively).

Figure 4: Effect of Atorvastatin on lipid parameter (TC,TG,LDL,HDL,LDL/HDL,VLDL) (mg/dl) in Diabetic Group

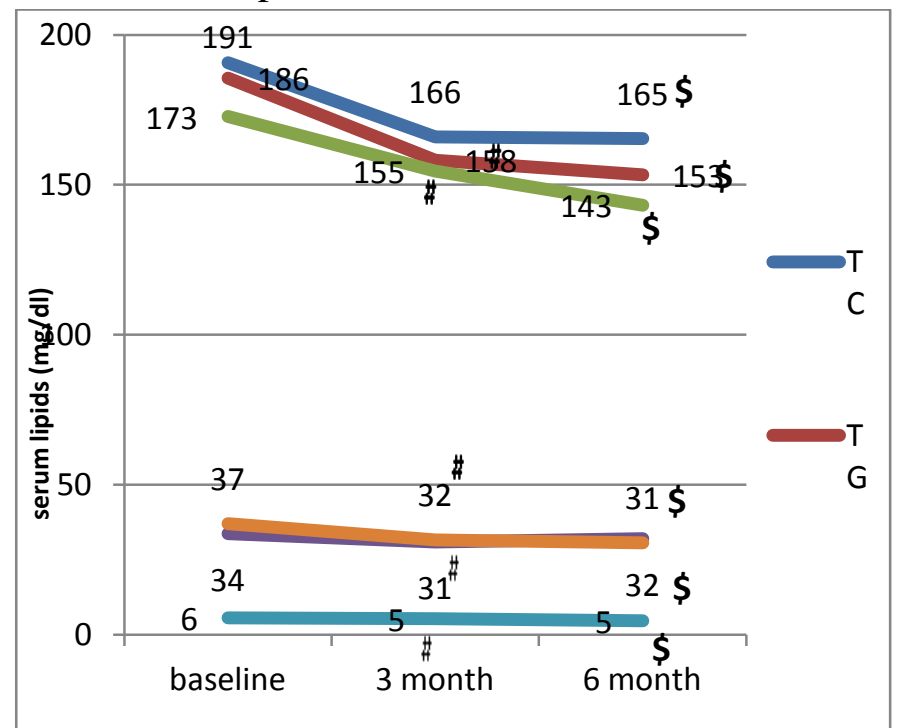

Figures are expressed as mean values $\pm 2 S D$ only.\# p-value $<0.005$ when baseline values were compared with 3 month values. $\$$ p-value $<0.005$ when baseline values were compared with 6 month values

Figure 5: Effect of Atorvastatin on lipid parameter (TC,TG,LDL,HDL,LDL/HDL,VLDL) (mg/dl) in Non- Diabetic Group

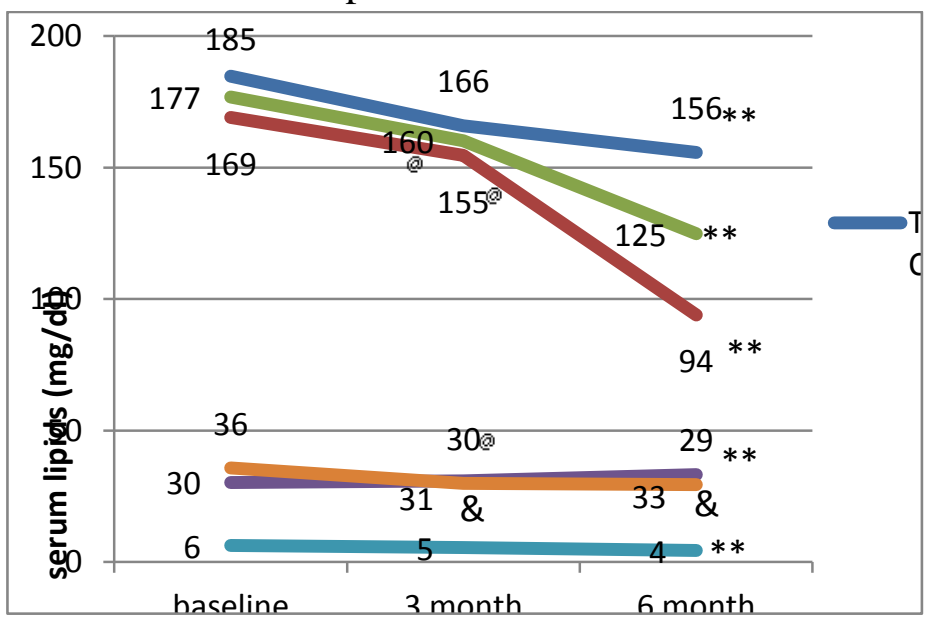

Figures are expressed as mean values \pm 2 SD only. @ p-value $<0.005$ when baseline values were compared with 3 month values. ${ }^{* *}$ p-value $<0.005$ when baseline values were compared with 6 month values. Significant rise in HDL values as, \&p-value $<0.0002$ when 3 month values were compared with that at 6 months and also baseline compared to 6 months.

When the various lipid parameters and FBG levels in the diabetic and non-diabetic groups were subjected to statistical tests for Pearson's coefficient of correlation. It was noted that in the Diabetic group, there was significant negative correlation between FBG and LDL/HDL ratio at 3 month. Similarly the positive correlation between FBG and HDL at baseline in non-diabetic group.(Table 2 ) When the various lipid parameters and PPBG levels in the diabetic and non-diabetic groups were subjected to statistical tests for Pearson's coefficient of correlation. .It was noted that when PPBG was compared with HDL, a statistically significant positive correlation found at 3 month.(Table 3)

Table 1. Baseline characteristics of the study population 


\begin{tabular}{|c|c|c|c|c|}
\hline \multicolumn{2}{|c|}{$\begin{array}{ll}\text { Parameter } & \text { Groups } \\
\end{array}$} & $\begin{array}{l}\text { Diabetic Group } \\
(\mathrm{n}=30)(\text { Group-I) }\end{array}$ & $\begin{array}{c}\text { Non-Diabetic Group } \\
(\mathrm{n}=30)(\text { Group-II })\end{array}$ & $\mathrm{p}$-value \\
\hline \multicolumn{2}{|c|}{ Age (years) } & $52.87 \pm 1.86$ & $52.60 \pm 1.43$ & 0.9101 \\
\hline \multirow{2}{*}{ Gender } & Males n (\%) & $20(66.66 \%)$ & $19(63.33 \%)$ & \multirow{2}{*}{0.7866} \\
\hline & Females n $(\%)$ & $10(33.34 \%)$ & $11(36.67 \%)$ & \\
\hline \multicolumn{2}{|c|}{ Weight $(\mathrm{kg})$} & $71.57 \pm 6.75$ & $65 \pm 11.59$ & 0.0651 \\
\hline \multicolumn{2}{|c|}{ Height $(\mathrm{cm})$} & $164.2+5.62$ & $155.8+4.91$ & 0.0883 \\
\hline \multicolumn{2}{|c|}{ FBG $(\mathrm{mg} / \mathrm{dl})$} & $138.4+13.33$ & $91.13+13.60$ & $<0.0001 * *$ \\
\hline \multicolumn{2}{|c|}{ PPBG (mg/dl) } & $247.9+35.16$ & $159.8+20.30$ & $<0.0001 * *$ \\
\hline \multicolumn{2}{|c|}{ Serum TC $(\mathrm{mg} / \mathrm{dl})$} & $190.6+27.05$ & $184.5+32.05$ & 0.4316 \\
\hline \multicolumn{2}{|c|}{ Serum LDL (mg/dl) } & $172.7+29.13$ & $178.8+28.76$ & 0.7872 \\
\hline \multicolumn{2}{|c|}{ Serum HDL $(\mathrm{mg} / \mathrm{dl})$} & $33.70+11.02$ & $30.23+8.47$ & 0.1772 \\
\hline \multicolumn{2}{|c|}{ LDL/HDL Ratio } & $5.65+1.98$ & $6.19+1.89$ & 0.2858 \\
\hline \multicolumn{2}{|c|}{ VLDL (mg/dl) } & $37.12+5.48$ & $35.71+4.45$ & 0.2868 \\
\hline \multicolumn{2}{|c|}{$\mathrm{TG}(\mathrm{mg} / \mathrm{dl})$} & $185.5+27.42$ & $178.6+22.26$ & 0.2868 \\
\hline
\end{tabular}

**p-value $<0.05$ is statistically significant. Values expressed as Mean \pm SEM.Normal values :FBG- Fasting Blood Glucose (75$110 \mathrm{mg} / \mathrm{dl}$ ), PPBG -Postprandial Blood Glucose (70-120 mg/dl). Serum total cholesterol (TC) (<200 mg/dl), Serum low density lipoproteins (LDL)( $<100 \mathrm{mg} / \mathrm{dl})$, Serum HDL ( $<40 \mathrm{mg} / \mathrm{dl}$-low) $(60 \mathrm{mg} / \mathrm{dl}$-high), LDL/HDL Ratio normally 1.66 - 2.5, TG (30$200 \mathrm{mg} / \mathrm{dl})$

Table 2: Correlation coefficients between fasting blood glucose and serum lipids in diabetic and nondiabetic group

\begin{tabular}{|c|c|c|c|c|c|c|c|c|c|c|c|c|c|}
\hline \multicolumn{2}{|c|}{$\begin{array}{l}\text { Parameter } \\
\text { Correlation }\end{array}$} & \multicolumn{2}{|c|}{ FBG and TC } & \multicolumn{2}{|c|}{$\begin{array}{c}\text { FBG and } \\
\text { TG }\end{array}$} & \multicolumn{2}{|c|}{$\begin{array}{l}\text { FBG and } \\
\text { LDL }\end{array}$} & \multicolumn{2}{|c|}{$\begin{array}{c}\text { FBG } \\
\text { and HDL }\end{array}$} & \multicolumn{2}{|c|}{$\begin{array}{l}\text { FBG and } \\
\text { LDL/HDL }\end{array}$} & \multicolumn{2}{|c|}{ FBG and VLDL } \\
\hline & & DM & $\begin{array}{c}\text { Non- } \\
\text { DM }\end{array}$ & DM & $\begin{array}{c}\text { Non- } \\
\text { DM }\end{array}$ & DM & $\begin{array}{l}\text { Non- } \\
\text { DM }\end{array}$ & DM & $\begin{array}{l}\text { Non- } \\
\text { DM }\end{array}$ & DM & $\begin{array}{l}\text { Non- } \\
\text { DM }\end{array}$ & DM & $\begin{array}{l}\text { Non- } \\
\text { DM }\end{array}$ \\
\hline \multirow{2}{*}{$\begin{array}{l}\text { Baselin } \\
\mathrm{e}\end{array}$} & $\mathrm{r}$ & -0.11 & 0.08 & 0.06 & 0.24 & $\begin{array}{c}0.0 \\
9 \\
\end{array}$ & $\begin{array}{c}- \\
0.17 \\
\end{array}$ & -0.07 & -0.37 & 0.13 & 0.18 & -0.06 & 0.24 \\
\hline & $\mathrm{p}$ & 0.55 & 0.66 & 0.73 & 0.21 & $\begin{array}{c}0.6 \\
3\end{array}$ & 0.36 & 0.73 & $0.04 \theta$ & 0.50 & 0.33 & 0.73 & 0.21 \\
\hline \multirow[t]{2}{*}{3 month } & $\mathrm{r}$ & $\begin{array}{c}- \\
0.054 \\
\end{array}$ & $\begin{array}{c}- \\
0.01 \\
\end{array}$ & 0.25 & 0.28 & $\begin{array}{c}0.1 \\
4 \\
\end{array}$ & $\begin{array}{c}- \\
0.07 \\
\end{array}$ & -0.29 & -0.21 & 0.37 & 0.10 & 0.23 & 0.27 \\
\hline & $\mathrm{p}$ & 0.78 & 0.95 & 0.18 & 0.14 & $\begin{array}{c}0.4 \\
6\end{array}$ & 0.71 & 0.12 & 0.26 & $0.04 \alpha$ & 0.59 & 0.22 & 0.15 \\
\hline \multirow[t]{2}{*}{6 month } & $\mathrm{r}$ & -0.20 & 0.04 & 0.01 & 0.21 & $\begin{array}{c}0.1 \\
7 \\
\end{array}$ & 0.12 & -0.06 & -0.14 & 0.13 & 0.11 & -0.04 & 0.21 \\
\hline & $\mathrm{p}$ & 0.28 & 0.83 & 0.96 & 0.26 & $\begin{array}{c}0.3 \\
6\end{array}$ & 0.53 & 0.74 & 0.45 & 0.51 & 0.56 & 0.83 & 0.26 \\
\hline
\end{tabular}

$\theta$-value $<0.05$ of Pearson's coefficient of correlation is statistically significant for FBG correlation with HDL in non-diabetics. $\alpha$-value $<0.05$ of Pearson's coefficient ofcorrelation statistically significant FBG correlation with LDL/HDL ratio in diabetics. 
Table 3: Correlation coefficients between Post Prandial Blood Glucose (PPBG) and serum lipids in diabetic group and non-diabetic groups

\begin{tabular}{|c|c|c|c|c|c|c|c|c|c|c|c|c|c|}
\hline \multicolumn{2}{|c|}{$\begin{array}{l}\text { Parameter } \\
\text { Correlation }\end{array}$} & \multicolumn{2}{|c|}{$\begin{array}{l}\text { PPBG and } \\
\text { TC }\end{array}$} & \multicolumn{2}{|c|}{$\begin{array}{l}\text { PPBG and } \\
\text { TG }\end{array}$} & \multicolumn{2}{|c|}{$\begin{array}{l}\text { PPBG and } \\
\text { LDL }\end{array}$} & \multicolumn{2}{|c|}{$\begin{array}{l}\text { PPBG } \\
\text { and HDL }\end{array}$} & \multicolumn{2}{|c|}{$\begin{array}{l}\text { PPBG and } \\
\text { LDL/HDL }\end{array}$} & \multicolumn{2}{|c|}{$\begin{array}{l}\text { PPBG and } \\
\text { VLDL }\end{array}$} \\
\hline & & $\mathrm{DM}$ & $\begin{array}{l}\text { Non- } \\
\text { DM }\end{array}$ & $\mathrm{DM}$ & $\begin{array}{l}\text { Non- } \\
\text { DM }\end{array}$ & DM & $\begin{array}{l}\text { Non- } \\
\text { DM }\end{array}$ & DM & $\begin{array}{l}\text { Non- } \\
\text { DM }\end{array}$ & DM & $\begin{array}{l}\text { Non- } \\
\text { DM }\end{array}$ & DM & $\begin{array}{l}\text { Non- } \\
\text { DM }\end{array}$ \\
\hline \multirow[t]{2}{*}{ Baseline } & $r$ & 0.04 & $-\overline{0}$ & $-\overline{-}$ & 0.29 & $\overline{-}-01$ & $-\overline{0}$ & 0.17 & 0.10 & -0.09 & -0.17 & -0.18 & 0.29 \\
\hline & $\mathrm{p}$ & 0.84 & 0.82 & 0.43 & 0.11 & 0.97 & 0.70 & 0.36 & 0.60 & 0.63 & 0.38 & 0.35 & 0.11 \\
\hline \multirow[t]{2}{*}{3 month } & $\mathrm{r}$ & $-\overline{0}$ & 0.05 & $-\overline{0}$ & 0.03 & 0.17 & $\begin{array}{l}- \\
0.17\end{array}$ & 0.36 & 0.06 & -0.18 & -0.18 & -0.18 & 0.03 \\
\hline & $\mathrm{p}$ & 0.75 & 0.81 & 0.33 & 0.87 & 0.37 & 0.37 & $\begin{array}{l}0.05 * \\
*\end{array}$ & 0.75 & 0.35 & 0.35 & 0.33 & 0.88 \\
\hline \multirow[t]{2}{*}{6 month } & $\mathrm{r}$ & -0.1 & 0.08 & 0.06 & $\overline{0}-03$ & 0.14 & $\begin{array}{l}- \\
0.11\end{array}$ & 0.07 & 0.07 & 0.03 & -0.16 & 0.03 & -0.03 \\
\hline & $\mathrm{p}$ & 0.56 & 0.67 & 0.77 & 0.87 & 0.47 & 0.58 & 0.73 & 0.70 & 0.86 & 0.39 & 0.89 & 0.86 \\
\hline
\end{tabular}

**p-value $=0.05$ of Pearson's coefficient of correlation is statistically significant for PPBG correlation with HDL in diabetics.

\section{Discussion}

Dyslipidemia is a primary major risk factor for Coronary Artery Disease (CAD). American Association of Clinical Endocrinologist (AACE) recommends 'Statins' as the drug of choice for LDL cholesterol reduction on the basis of findings from morbidity and mortality in certain outcome trial ${ }^{[9]}$. High-dosage therapy also significantly reduces nonfatal MI, stroke, unstable angina, and revascul-arization risk ${ }^{[9,10]}$. Diabetes mellitus also increases cardiovascular risk to the extent that it is considered a CAD risk equivalent ${ }^{[11]}$. In fact certain studies point out that the risk of myocardial infarction in patients with diabetes mellitus without a history of myocardial infarction is as high as that in patients without diabetes mellitus who had myocardial infarction ${ }^{[12]}$. Secondary prevention statin studies such as HPS (Heart Protection Study) showed that there is significant risk reduction among patients with diabetes. Diabetes affects virtually all lipids and lipoproteins and dyslipidemia is a consistent finding in people with type 2 diabetes. Patients with type 2 diabetes also tend to have a preponderance of atherogenic small dense LDL [13-15]

In the present study 60 diagnosed cases of dyslipidemia - 30 in Diabetic Group and 30 in Non-diabetic Group, who as per clinician, were deemed to receive Atorvastatin $10 \mathrm{mg}$ OD and these cases were studied for the period of 6 month for their effect on FBG and PPBG, lipid profile marker i.e. TC, TG, LDL, HDL, LDL/HDL and VLDL. The Diabetic Group showed mean age 52.87 years and Non-diabetic Group showed mean age 52.60 years when both groups were compared for age. No statistically significant difference was found in both groups. A study conducted by Tadashi Yamakawa et al ${ }^{[16]}$ showed mean age as 59.7 years in Diabetic Group. Therefore the occurrence of type-2 Diabetes is noted earlier in this study and is probably attributed to the ethnic variation in population and a high average Body Mass Index (BMI) in the diabetic group. The average BMI was 28.98 in diabetic groupin the present study which was higher when compared to the finding by Risto et al ${ }^{[17]}$ who reported an average BMI of 24.9 in 67 diabetic patients.

Both diabetic and non-diabetic group showed statistically insignificant increase in mean FBG levels from baseline to three months and also from 3 month to 6 month. ( $>0.05$ ). Only the diabetic group showed statistically significant increase in mean FBG levels at 6 month $(\mathrm{p}=0.0021)$ when the values were compared to that at baseline values. A study by Murakami et al ${ }^{[18]}$ showed that after Atorvastatin $5 \mathrm{mg}$ for 3 month 99 or $10 \mathrm{mg}$ for 2 month use resulted in significant increase in mean FBG in Diabetic patients, whereas in present study Atorvastatin (10mg/day) for 6 months 
resulted in significant rise in mean FBG in diabetic group only. A study by Sukhija et al [19] showed that in non- diabetics, mean FBG increased with statin use from $98 \mathrm{mg} / \mathrm{dl}$ to 105 $\mathrm{mg} / \mathrm{dl}$ and in diabetics, mean FBG increased with statin use from $102 \mathrm{mg} / \mathrm{dl}$ to $141 \mathrm{mg} / \mathrm{dl}$ i.e. statistically significant increase in mean FBG with statin use ( $\mathrm{p}<0.0001)$. So the statin use was associated with a rise of mean FBG in patients with and without diabetes at 2 years .These findings are contradictory to that of the present study probable reason being that alteration in mean FBG and PPBG in non-diabetic patients was noted for a shorter duration of just 6 months.

In present study, as regards to the change in mean PPBG levels at all visits; in non-diabetic group there was no statistical significant change $(\mathrm{p}>$ 0.05). On the contrary, Diabetic group showed statistically significant increase in mean PPBG levels from baseline to 3 months and 6 month. ( $p$ $=0.0052$ and $\mathrm{p}=0.0054$ respectively). This increase was also observed from 3 month to 6 month $(\mathrm{p}=0.0021)$. Therefore despite of giving the standard treatment for diabetes; in this population there was a significant rise in mean PPBG values over every 3 months and there was deterioration of glycemic control due to Atorvastatin $10 \mathrm{mg}$.A multi-centric randomized control trial conducted by Sabitine M.S. et al ${ }^{[18]}$ concluded that high dose of Atorvastatin (80 mg/day) might deteriorate glycemic control.

Important reasons for worsening of blood glucose were studied by Tadashi Y et al ${ }^{[16]}$ like Statins can compromise glycemic control by decreasing level of metabolites such as isoprenoid, geranylgeranyl pyrophosphate, ubiquion. Isoprenoidis known to enhance glucose uptake by up regulating the membrane transporter protein glucose transporter 4, which has role in glucose uptake by adipocytes. Another reason could be the increased production of plasma derived LDL cholesterol as a compensatory response to de novo cholesterol synthesis inhibition might result in direct inflammation and oxidation within the $\beta$ cell. The functional and structural integrity of $\beta$ cells is compromised, impairing insulin secretion as a result of cellular apoptosis.

Another study by Sattar N. et al ${ }^{[20]}$ showed that statin therapy was associated with a $9 \%$ increased risk for incident diabetes i.e. statin therapy is associated with a slightly increased risk of development of diabetes. Such observation were not made as in the present study ,a single dose of $10 \mathrm{mg}$ of Atorvastatin was used which was less than the dose used by Sattar N. et al. Conflicting result was presented by another multi-centric randomized trial studied by Sever P.S et al ${ }^{[20]}$ who studied that Atorvastatin was not associated with development of diabetes mellitus. An interesting study by Huptas S. et al ${ }^{[21]}$ showed that Atorvastatin $10 \mathrm{mg} /$ day resulted in significant reduction in mean FBG level and borderline reduction of insulinin diabetic patients.

In present study, a significant negative co-relation was observed between mean FBG and HDL in non-diabetic patients receiving Atorvastatin $10 \mathrm{mg} /$ day $(\mathrm{r}=-0.37, \mathrm{p}=0.04)$.It is due to the nonsignificant change in mean FBG along with a steady significant rise in mean HDL from baseline in this group. In the Diabetic group receiving Atorvastatin $10 \mathrm{mg} /$ day a significant positive corelation was observed between mean FBG and mean LDL/HDL ratio at 3 months $(r=0.37$, $\mathrm{p}=0.04$ ). This is possibly due to little fall in LDL along with significant fall in HDL hence altering the ratio .This positively co-related to the significant rise in mean FBG with the use of Atorvastatin. An interesting finding was the positive correlation $(\mathrm{r}=0.36, \mathrm{p}=0.05)$ between mean PPBG levels and mean HDL levels noted in the Diabetic group at 3 months. This is due to the transient non-significant rise in mean HDL levels from 3months to 6 months along with the significant rise in mean PPBG levels in this group. Other correlations between blood sugar levels and lipid parameters were not significant .Many investigators have tried to explore the physiological co-relation between such parameters in diabetic patients. Reddy S.A. et al ${ }^{[22]}$ investigated the correlation between lipid parameter and glycemic control in diabetic patients with 
dyslipidemia not on any medication. Results of that study stated that the FBG has direct correlation with TC,TG and LDL but it was insignificantly correlated with HDL. A study by Zhang L et a ${ }^{[23]}$ showed that FBG exhibited direct correlations with cholesterol, TG and LDL and inverse correlation with HDL $(\mathrm{p}<0.05)$. In the present study the Atorvastatin in a dose of $10 \mathrm{mg}$ had a lipid lowering effect in diabetics but also caused deterioration of glycemic control therefore results of the previous studies cannot be extended to this current study. In fact in the diabetic group the maximum lipid lowering effect of Atorvastatin $(10 \mathrm{mg})$ was achieved by the third week itself as not significant fall in lipid parameters were seen when their mean values at 3 months were compared with that at 6 months. But the deterioration of FBG and PPBG due to Atorvastatin (10 $\mathrm{mg}$ ) was seen in these patients at 3 months and 6 months as compared to baseline values

\section{Conclusion}

With the results of present study $10 \mathrm{mg} /$ day of Atorvastatin for 6 months did not affect FBG or PPBG in Non-diabetic patients significantly, but there was a significant deterioration in the blood glucose control - fasting and post-prandial, in the diabetic patients after 6 months and 3 months of drug use respectively. Atorvastatin $10 \mathrm{mg}$ is an effective hypolipidemic drug and has adequate lipid lowering effects in diabetic and nondiabetics. Only one important finding was that it also significantly decreased HDL in diabetics after 3 months of use which is not a welcome effect. Ceiling hypolipide-mic action of Atorvastatin 10 mg was in obtained in Diabetes patients at 3 month and was maintained upto the end of study period. But the deterioration of glycemic control started after 3 months and significantly worsened till the end of study period i.e 6 months. Therefore treating physicians should advise routine monitoring of blood glucose in patients on Atorvastatin atleast 3 monthly if non-diabetic. They should also try to titrate down the dose of Atorvastatin after 3 months of treatment in diabetic patient (if clinically permissible) while maintaining the optimum hypolipidemic effect and minimal alteration in glycemic control.

\section{References}

1. Misra A, Luthra K, Vikram NK. Dyslipidemia in Asian Indians: Determinants and Significance. JAPI .February $2004 ; 52: 137-142$ (Abstract) Available at : http://www.ncbi.nlm.nih.gov/pubmed/156 56049

2. Dean G. Smith. Epidemiology of Dyslipidemia and Economic Burden on the Healthcare System. Am J Manag Care. 2007; 13: S68-S71 Available at: http://www.ajmc.com/journals/supplement /2007/2007-06 vol13-n3suppl/jun072502ps69-s71/

3. Chandra KS , Bansal M., Nair T., Iyengar SS ,Gupta R., Manchanda SC et al. Consensus statement on management of dyslipidemia in Indian subjects. Indian heart journal. 2014; 66:S1-S51 Available at : http://www.ncbi.nlm.nih.gov/pmc/articles/ PMC4297876/

4. Carter AA, Tara G, Ximena Camacho , Juurlink DN, Shah BR, Mamdani MM. Risk Of Incident Diabetes Among Patient Treated With Statin, A Population Based Study. BMJ 2013;346:f2610 doi: 10.1136/bmj.f2610 Available at : http://www.ncbi.nlm.nih.gov/pmc/articles/ PMC3662830/

5. US Food and Drug Administration. FDA drug safety communication: important safety label changes to cholesterollowering statin drugs. 2012. Available at: www.fda.gov/Drugs/DrugSafety/ucm2931 01.htm

6. Culver AL, Ockene IS, Balasubramanian R, Olendzki BC, Sepavich DM, Wactawski W et al. Statin use and risk of diabetes mellitus in postmenopausal women in the Women's Health Initiative. Arch Intern Med.2012;172:144-152 Available at 
http://www.ncbi.nlm.nih.gov/pubmed/222 31607

7. KatzungBG, Susan B. M, Antony. JT. Agents used in Dyslipidaemia. Basis \& Clinical Pharmacology .11th edi .p: $605-$ 607

8. BucoloG., David H.-Clin Chem. 1973,19,476. Esder T.W.,Michrina CAJournal of biochemistry .Philadelphia PA.

9. Paul S. Jellinger, Donald Smith, Adi Mehta, Om Ganda, Yehuda Handelsman, Helena Rodbard, Mark Shepherd et al. American association of clinical endocrinologists' guidelines for management of dyslipidemia and prevention of atherosclerosis, endocrine practice. 2012;18(supplement 1) Available at : http://journals.aace.com/doi/abs/10.4158/E P.18.S1.1?journalCode=endp

10. Alberti , Robert H. Eckel, Scott M. Grundy, Paul Z. Zimmet, James I. Cleeman, et al. Harmonizing the Metabolic Syndrome A Joint Interim Statement of the International Diabetes Federation Task Force on Epidemiology and Prevention; National Heart, Lung, and Blood Institute; American Heart Association; World Heart Federation; International Atherosclerosis Society; and International Association for the Study of Obesity . Circulation. 2009;120:1640-1645. Available at : http://circ.ahajournals.org/content/120/16/ 1640.full.pdf + html

11. Haffner SM, Lehto S, Ronnemaa T, Pyorala K, Laakso M. Mortality from coronary heart disease in subjects with type 2 diabetes and in nondiabetic subjects with and without prior myocardial infarction. N Engl J Med 1998;339:229-34. Available at http://www.nejm.org/doi/pdf/10.1056/NEJ M199807233390404

12. Turner R, Cull C, Holman R. United Kingdom prospective diabetes study 17: a 9-year update of a randomized, controlled trial on the effect of improved metabolic control on complications in non-insulin dependent diabetes mellitus. Ann Intern Med .1996 ; 124:136-45. Available at : http://annals.org/article.aspx? articleid=709 358 (Abstract)

13. Chiquette E, Chilton R. Cardiovascular disease: much more aggressive in patients with type 2 diabetes. Curr Atheroscler Rep .2002; 4: 13442. Available at : http://link.springer.com/article/10.1007/s1 1883-0020037-z (Abstract)

14. Reaven GM, ChenY-DI, Jeppesen J, Maheux P, Krauss RM. Insulin resistance and hyperinsulinemia in individuals with small, dense, low density lipoprotein particles. J ClinInvest .1993; 92:141-6. Available at http://www.ncbi.nlm.nih.gov/pmc/articles/ PMC293550/pdf/jcinvest00028-0159.pdf

15. Austin MA, Edwards KL. Small, dense low density lipoproteins, the insulin resistance syndrome and noninsulindependent diabetes. Curr Opin Lipidol .1996; 7:167-71. Available at : http://www.ncbi.nlm.nih.gov/pubmed/881 8515? dopt=Abstract

16. Tadashi Y,Tatsora $\mathrm{T}$,shun-ichi $\mathrm{T}$, kazauki $\mathrm{K}$,Yasuo $\mathrm{T}$. influence of pitavastatin on glucose tolerance in patients with type 2 diabetis mellitus. Journal of atherosclerosis and thrombosis .15(5) : 269-275. Available at

http://europepmc.org/abstract/MED/18981 652 (Abstract)

17. Risto KH, Jorma SV, Saarimaa H . Correlation of Serum Lipids with Diabetes Control in Sulfonylurea-treated Diabetic Patients, diabetes care, novemberdecember 1984 7(6) : 575-579

18. Jun kasasi . Statins: beneficial or adverse for glucose metabolism .journal of atherosclerosis and thrombosis. 2006 ; 13(3) :123-129 Available at : http://www.researchgate.net/publication/6 951098_ Statins_Beneficial_orAdverse_ for_Glucose_Metabolism (Abstract) 
19. Sukhija, Rishi, Prayaga, Sastry, Marashdeh, Mohammad et al . Effect of Statins on Fasting Plasma Glucose in Diabetic and Nondiabetic Patients, Journal of Investigative Medicine. March 2009 ; 57 (3) : 495499. Available at:http://journals.lww.com/jinvestigativem ed/Abstract/2009/03000/Effect_ofStatins_ on_Fasting_Plasma_Glucose_in.4.aspx (Abstract)

20. NaveedSattar, David Preiss, Heather M Murray, Paul Welsh, Brendan M Buckley, Anton JM de Craen et al . Statins and risk of incident diabetes: a collaborative metaanalysis of randomized statin trials. Lancet . 27 February-5 March 2010 ; 375(9716) : 735-742. Available at http://www.thelancet.com/pdfs/journals/la ncet/PIIS01406736\%2809\%2961965-6.pdf (Abstract)

21. HuptasS ,Geiss HC, Otto C, Parhofer KG. Effect of atorvastatin (10 mg/day) on glucose metabolism in patients with the metabolic syndrome.Am J Cardiol. 2006 Jul 1; 98(1):66-9. Available at : http://www.ncbi.nlm.nih.gov/pubmed/167 84923 (Abstract)

22. Reddy AS ,Meera S, Ebenezer W, Kumar JS. Correlation between glycemic control and lipid profile in type 2 diabetic patients: hba1c as an indirect indicator of dyslipidemia. Asian journal of pharmaceutical and clinical research. 2014; 7(2): 153-155. Available at http://innovareacademics.in/journals/index .php/ajpcr/article/view/977 (Abstract)

23. Zhang L, Qiao Q, Tuomilehto J, Hammar $\mathrm{N}$, Janus ED, Soderberg $\mathrm{S}$ et al. Blood lipid levels in relation to glucose status in seven populations of Asian origin without a prior history of diabetes: the DECODA study. Diabetes Metab Res Rev. 2009 Sep ; 25 (6): 549-57. Available at : http://onlinelibrary.wiley.com/doi/10.1002 /dmrr.994/epdf 